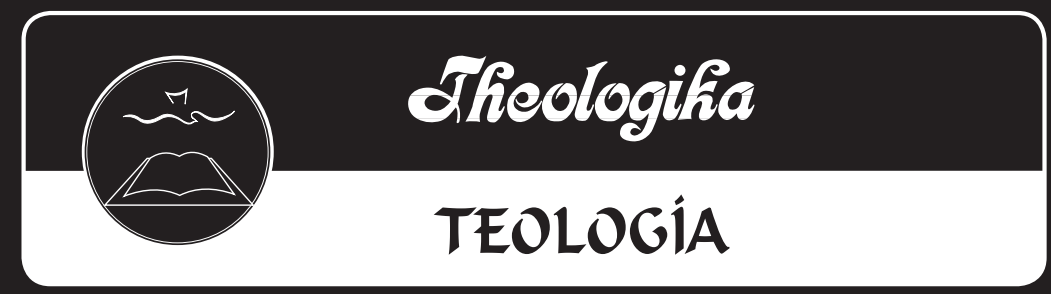

La "Nueva Perspectiva Paulina" 0 "Las Nuevas Perspectivas Paulinas": Ed Parish Sanders y las tendencias teológicas recientes sobre los eseritos paulinos 
Silvia Scholtus

Universidad Adventista del Plata 


\section{RESUMEN}

“La 'Nueva Perspectiva Paulina' o 'Las Nuevas Perspectivas Paulinas': Ed Parish Sanders y las tendencias teológicas recientes sobre los escritos paulinos" - Desde 1977, con la publicación de la obra Paul and Palestinian Judaism editada por P. Sanders, (Universidad Duke de Carolina del Norte en Estados Unidos), el estudio de los escritos paulinos ha sufrido un antes y un después. En su obra, Sanders presentó su extenso estudio comparativo entre la literatura judía y los escritos paulinos. El argumento de Sanders es que la comprensión luterana tradicional de la teología judía y de Pablo es incorrecta. La propuesta de Sanders fue denominada por James D. G. Dunn (obispo y teólogo anglicano), en 1982, como "Nueva Perspectiva Paulina" (NP). Por lo tanto, la NP es un intento por extraer las cartas paulinas del marco Luterano/ Reformista e interpretarlas basadas en lo que se dice ser una comprensión más apropiada del judaísmo del primer siglo, obtenido de los propios escritos de esa época, y revisando los últimos estudios sobre judaísmo asentados en los hallazgos arqueológicos del s. XX. ¿Quién tiene razón?, ¿la"Antigua Perspectiva sobre Pablo" (AP, o luteranos y reformistas) o la NP de Sanders?, ¿hacia dónde se inclina la balanza en esta discusión?

Este estudio analiza la reacción que provocó la propuesta de Sanders, cuáles son los temas discutidos actualmente para entender las áreas en que se puede contribuir al debate y que sirva como referencia para quienes están interesados en el estudio de los escritos paulinos.

Palabras clave: Nueva Perspectiva Paulina, Antigua Perspectiva Paulina, E. P. Sanders, Soteriología, Escritos paulinos y Judaísmo. 


\section{SUMMARY}

"New Pauline Perspective' or 'New Pauline Perspectives': Ed Parish Sanders and Recent Theological Tendencies on Pauline Writings" - Since 1977, with the publication of the work Paul and Palestinian Judaism of Ed P. Sanders (Duke University of North Carolina in the United States), the study by Paul's writings have had a before and after. In his book, Sanders presented his extensive comparative study of Jewish literature and the Pauline writings. Sanders' argument is that the traditional Lutheran understanding of Jewish theology and Paul is incorrect. Sanders' proposal was named by James D.G. Dunn (Anglican bishop and theologian), in 1982, as the "Pauline New Perspective" (PN) Therefore, the $\mathrm{PN}$ is an attempt to extract the Pauline letters from the Lutheran/Reformed context and interpret them based on what is said to be a more appropriate understanding of first-century Judaism, obtained from the writings of that time themselves, and reviewing recent studies on Judaism settled in archaeological findings of the 20th century. Who is right?, the "Old Perspective on Paul" (OP), or Lutherans and Reformists or Sanders PN?, Where does the balance tip in this discussion? This study analyzes the reaction that caused Sanders' proposal, which are the issues currently discussed, to understand the areas in which they can contribute to the debate and serve as a reference for those interested in the study of Paul's writings.

Keywords: Pauline New Perspective, Pauline Old Perspective, E. P. Sanders, Soteriology, Pauline Writings and Judaism. 


\section{“LA'NUEVA PERSPECTIVA PAULINA' O 'LAS NUEVAS PERSPECTIVAS PAULINAS': ED PARISH SANDERS Y LAS TENDENCIAS TEOLÓGICAS RECIENTES SOBRE LOS ESCRITOS PAULINOS"}

“Entonces, comenzando por Moisés y por todos los profetas, les explicó lo que se refería a él en todas las Escrituras ... les abrió el entendimiento para que comprendieran las Escrituras." (Luc 24:27, 45)

“Escudriñad las Escrituras, porque a vosotros os parece que en ellas tenéis la vida eterna, y ellas son las que dan testimonio de mí. (Juan 5:29)

\section{Introducción}

El área de los estudios bíblicos no ha visto una revolución más dramátrica en años recientes que la generada en los estudios sobre el judaísmo del primer siglo. En particular, la relación que tienen con los escritos paulinos. La publicación de Paul and Palestinian Judaism de Ed. P. Sanders (1977) es una propuesta desafiante que se conoce como la "Nueva Perspectiva Paulina" (NP) y que intersecta una amplia gama de otros temas en los estudios sobre Nuevo Testamento (NT). Es un cambio significativo sobre la forma en que algunos eruditos, especialmente protestantes, interpretan los escritos del apóstol Pablo. Es tan desafiante que aquellos eruditos que no concuerdan con su tesis, deben interactuar con ella para que se los tome en serio. 
La obra de Sanders tuvo amplia difusión y provocó un cambio de paradigma de proporciones significativas. Varios eruditos importantes del NT, después de 1977, se encontraron a sí mismos afectados y concordando con Sanders y su propuesta de interpretación de los escritos paulinos, en conceptos que antes se consideraban una polémica paulina sobre la "teología del mérito". Este cambio no continuó sin ser desafiado. Varios eruditos han presentado su resistencia a la tesis de Sanders. La NP ha sido en todo sentido un debate interno entre los eruditos protestantes. Varios eruditos conservadores protestantes se sienten comprensiblemente nerviosos por cualquier intento de reinterpretar los escritos paulinos debido al peso teológico que los protestantes han dado siempre a la lectura de las cartas paulinas bajo la influencia luterana, ${ }^{1} \mathrm{y}$, por lo tanto, reconocen que se debe responder a Sanders en sus propios términos.

De esto surge las siguientes inquietudes: ¿Quién tiene razón?, ¿la“Antigua Perspectiva sobre Pablo" (AP, o luteranos y reformistas) o la NP de Sanders?, ¿hacia dónde se inclina la balanza en esta discusión?, ¿quiénes son los que opinan actualmente?

En vista de este debate, esta revisión tiene como objetivos: (a) presentar una breve perspectiva histórica sobre el trasfondo teológico del surgimiento de la

${ }^{1}$ Véase por ejemplo la fuerte reacción de Jack Hughes, "The New Perspective's View of Paul and the Law", en The Master's Seminary Journal 16:2 (otoño 2005) 261-276, disponible en http://www.thepaulpage.com/newperspective/around-the-web/articles-challenging-the-new-perspective/; Internet (consultada el 7 de octubre de 2013) [en formato PDF format]. Esta página contiene las posturas de varios téologos sobre la NP. 
NP enfocado particularmente en describir algunos de sus conceptos claves así como las reacciones que ha provocado entre los eruditos; (b) auxiliar al lector interesado en entender los escritos paulinos al conocer sintéticamente esta discusión. Por lo tanto, los pasos a seguir en esta presentación es identificar los elementos históricos del surgimiento de la AP, los conceptos teológicos en revisión con sus exponentes principales y las reacciones de distintos grupos religiosos dentro del cristianismo. La conclusión tiene el objetivo de invitar a contribuir enriqueciendo el debate con futuros estudios.

\section{Perspectiva histórica}

Desde la Reforma Protestante (c. 1517), los estudios sobre los escritos paulinos se han visto influenciados por los puntos de vista luteranos y reformistas que adscriben a los atributos negativos que se asocian con el Catolicismo Romano del s. XVI hasta el judaísmo del s. I. Estos puntos de vista luteranos (Martín Lutero) y reformistas (Juan Calvino) sobre los escritos paulinos se denominan la "Antigua Perspectiva sobre Pablo" (AP). La "Nueva Perspectiva" (NP) es un intento por extraer las cartas paulinas de este marco Luterano/Reformista e interpretarlos basados en lo que se dice ser una comprensión del judaísmo del primer siglo, obtenido de los escritos de esa época.

Pablo, especialmente en su epístola a los Romanos, define que la justificación es por la fe en Jesucristo y no por la obras de la Ley. En la AP se entendía que Pablo discutía que las buenas obras de los cristianos no serían un factor salvífico, sólo su fe. Para Lutero la doctrina 
de la justificación por la fe es la más significativa para la iglesia cristiana. De acuerdo con la NP, Pablo sólo estaba cuestionando observancias como la circuncisión y las leyes dietarias, no las buenas obras en general. Es decir que si la NP es correcta acerca de las enseñanzas de la teología paulina, los reformadores podrían estar errados en cuanto a la cuestión principal de la soteriología de la Reforma.

Pero antes de seguir avanzando en el análisis de la NP, se describe brevemente el trasfondo teológico del momento en que surgió.

\section{Trasfondo teológico}

En 1963, el teólogo luterano Krister Stendahl escribió un artículo donde discutía que el punto de vista típico luterano sobre la teología del apóstol Pablo no encajaba con declaraciones en los escritos paulinos, $\mathrm{y}$, de hecho, que estaba más basado en un error de presuposiciones acerca de las creencias paulinas que en una cuidadosa interpretación de sus escritos. Este autor, por lo tanto, propuso que Pablo tenía una conciencia fuerte y no se dejó manejar por sentimientos de culpa personal como Agustín y Lutero. ${ }^{2}$ Por cierto, esta discución todavía sigue vigente ¿cuáles son realmente las presuposiciones paulinas? Existen antecedentes de otros autores que con anterioridad a Sanders propusieron una revisión de los conceptos

${ }^{2}$ Krister Stendahl, "The Apostle Paul and the Introspective Conscience of the West", Harvard Theological Review 56 (1963) 199-215; reimpreso en Paul among Jews and Gentiles (London: SCM, 1976), 76-96. 
sobre el judaísmo del período del Segundo Templo. ${ }^{3} \mathrm{C}$. G. Montefiore argumentó que el judaísmo que Pablo conocía era una fría forma de la diaspora judía y no el rabinismo judío. ${ }^{4}$ G. F. Moore supuso que los escritores cristianos estaban influenciados por un deseo apologético de ver en el judaísmo la antítesis de la gracia. ${ }^{5}$ Sin embargo, la que causó un impacto importante fue la propuesta de E. P. Sanders. Irónicamente, la tesis de Sanders, que pone en debate opiniones sostenidas hace mucho tiempo respecto al judaísmo como una "teología del mérito" y que, como se ha visto, venía siendo cuestionada por otros autores, no es revolucionaria de por sí. ¿Quién fue Ed Parish Sanders?

En 1977, E. P. Sanders (1937-2005 se jubiló), un teólogo metodista de NT, de la Universidad Duke de Carolina del Norte en Estados Unidos, ${ }^{6}$ publicó su obra

${ }^{3}$ Preston Sprinkle presenta aspectos importantes y antecesores de Sanders en las obras de G. F. Moore, K. Stendahl, George Howard, Joseph Tyson y N. A. Dahl (Preston M. Sprinkle, “The Old Perspective on the New Perspective: A Review of Some 'Pre-Sanders' Thinkers", Themelios 30 [2005] 21-31). Véanse también W. D. Davies, Paul and Rabbinic Judaism: Some Rabbinic Elements in Pauline Theology (4th ed.; Philadelphia: Fortress, 1980 [1948]); Samuel Sandmel, The Genius of Paul: A Study in History (New York: Farrar, Straus and Cudahy, 1958); H. J. Schoeps, Paul: The Theology of the Apostle in the Light of Jewish Religious History (Philadelphia: Westminster, 1961).

${ }^{4}$ C. G. Montefiore, Judaism and St. Paul: Two Essays (New York: Dutton, 1915).

${ }^{5}$ G. F. Moore, "Christian Writers on Judaism", Harvard Theological Review 14 (1921) 197-254; idem, Judaism in the First Centuries of the Christian Era - 2 vols. (Harvard: HUP, 1927).

'Sanders nació y creció en Grand Prairie, Texas. Estudio en el Wesleyan College, Fort Worth (1955-1959) y la Escuela de Teología de Perkins en Southern Methodist University, Dallas (1959-1962). Estudio por un año (1962-1963) en Göttingen, en la University of Oxford y en Jerusalem. 
titulada Paul and Palestinian Judaism [Pablo y el judaísmo palestinense]. ${ }^{7}$ Ésta fue fruto de una beca que recibió para estar un año en Jerusalén (1968, del Concilio de Canadá), donde estudió sobre rabinismo judío. En su obra, Sanders presentó su contribución particular debido a que hizo:

1. Un estudio extenso de fuentes primarias con su singular inquietud en mente sobre la literatura judía.

2. Además escribió un libro donde comparó esta literatura con un análisis de los escritos paulinos. Este libro sería leído extensamente con posterioridad en la comunidad de la erudición bíblica.

Pero, ¿cuáles son los temas que expuso Sanders en esta obra que provocaron reacciones entre los estudiosos?

Entre septiembre de 1963 y mayo de 1966, Sanders estudió su doctorado en el Union Theological Seminary, New York. Su tesis se tituló "The Tendencies of the Synoptic Tradition" (publicada en 1969) y supervisada por W. D. Davies. Enseñó en la Universidad McMaster (Hamilton, Ontario) desde 1966 a 1984. En 1968, obtuvo apoyo del Consejo de Canadá para pasar un año en Israel, estudiando el judaísmo rabínico. En 1984, fue profesor titular en Exégesis de las Sagradas Escrituras en la Universidad de Oxford y miembro del Queen's College, hasta que se trasladó a la Universidad Duke en 1990. Sanders se considera a sí mismo un "protestante liberal, moderno y secularizado" en su libro Jesus and Judaism (Philadelphia: Fortress Press, 1985). John P. Meier lo denominó "protestante posliberal".

${ }^{7}$ E. P. Sanders, Paul and Palestinian Judaism: A Comparison of Patterns of Religion (Fortress Press, Philadelphia, 1977). Disponible en: http://www. philosophyandscripture.org/Issue2-2/Sanders/Sanders.html; Internet (consultada el 15 de septiembre de 2013). 


\section{Síntesis de los conceptos de Sanders}

$\mathrm{Su}$ argumento principal es que la comprensión luterana tradicional de la teología judía y paulina es fundamentalmente incorrecta. Es decir que la interpretación cristiana tradicional de que Pablo estaba condenando el legalismo rabínico fue un malentendido sobre la forma de pensar del judaísmo y de Pablo. En especial cuando se asume un nivel de individualismo en estas doctrinas que no estaban realmente presentes y se ignoran las nociones judías de beneficio grupal o privilegio colectivo. El primer punto fundamental que buscó establecer Sanders fue que la religión judía no era una escalera por la cual los judíos trepaban intentando ganar el favor de Dios mediante obras meritorias, sino que el judaísmo era una religión a la que caracterizó como "nomismo pactual" (covenantal nomism). Con esto, Sanders quiere decir que según las obras del judaísmo uno es miembro del pueblo en virtud del pacto que Dios hizo con Abrahán, y se permanece en él guardando la Ley. ${ }^{8}$ Sanders, por lo tanto, argumenta que la diferencia clave entre el judaísmo pre-cristiano y las enseñanzas paulinas se pueden encontrar en las ideas de cómo una persona llega a ser parte del pueblo de Dios.

Un segundo punto de Sanders, es que el judaísmo emplea los términos sobre "justo" (y el grupo dik- en griego) en forma diferente a Pablo. En Pablo, es gene-

${ }^{8 “}$ En pocas palabras, el pacto nomista es la visión de que el lugar en el plan de Dios se establece sobre la base del pacto y que el pacto requiere la respuesta adecuada del hombre en obediencia a los mandamientos, proveyendo medios de expiación para la transgresión". (Sanders, Paul and Palestinian Judaism, 75). 
ralmente un verbo traducido como "justificar", empleado como un término de transferencia que describe el movimiento hacia la salvación. Para el judaísmo es un adjetivo que hace referencia al comportamiento correcto de quienes ya eran parte del pacto. ${ }^{9}$ Estos énfasis conceptuales se pueden notar en el trato que los grupos del judaísmo ejercían al perseguir a Cristo y los apóstoles durante su ministerio inclusivo de la salvación a los gentiles.

Un tercer aspecto es que Sanders aboga que las creencias paulinas conforman un patrón que denominó "escatología participacionista" (Participacionist Eschato$\log y)$. Mediante este patrón, Pablo explica que la única forma por la que uno llega a formar parte del Pueblo de Dios es por la fe en Cristo ("muriendo con Jesús") y que el Antiguo Pacto ya no era suficiente. Pero, una vez que el converso ingresa a la fe, es decir, esta "dentro", se requiere del cristiano un comportamiento apropiado basado en las Escrituras judías, pero sin tener en cuenta todos los aspectos de ésta. Ambos modelos, "nomismo pactual" y "escatología participacionista", requieren de la gracia de Dios para la elección (admisión) y para el comportamiento del individuo. ${ }^{10}$ La línea divisoria

${ }^{9}$ Ibíd., 544-545. La excepción es Qumran, que también usan los términos "justo" y derivados como un término transferencial, aunque en forma diferente a lo que lo hace Pablo. En los escritos de Qumran se emplea con referencia a aquellos que eran justos, no para hacer referencia a una justificación inmerecida (véase Tim Gallant, "Covenantal nomism? A comparative review of Sanders and Carson et al.", en Rabbi Saul: Studies in Paul and Second Temple Judaism, disponible en http:/ / www.rabbisaul.com/ articles/nomism.php; Internet [consultada el 7 de octubre de 2013]).

${ }^{10}$ En el adventismo el concepto es diferente. Por ejemplo, la escritora Elena de White, co-fundadora de la IASD, dice que "cuando las personas 
entre el judaísmo y Pablo se encuentra en la insistencia paulina de la fe en Cristo como la única forma para ser elegido. No obstante, Sanders enfatiza que Pablo también amaba las buenas obras y que, cuando sus palabras son tomadas dentro del contexto, se nota que Pablo abogaba por las buenas obras como adición a la fe en Cristo. ${ }^{11}$

Sanders continuó publicando libros y artículos en esta área, y pronto se le unió el erudito James D. G. Dunn, teólogo anglicano. ${ }^{12}$ El siguiente mayor libro

responden a la atracción de Cristo y ven a Jesús como el Rey que sufrió en la cruz del Calvario, se unen con Cristo; se convierten en los elegidos de Dios, no por sus obras sino por la gracia de Cristo. Porque todas sus buenas obras son obradas por el poder del Espíritu de Dios. Todo es de Dios, y no de ellos" (Signs of the Times, 2 de mayo de 1892, reproducido y traducido en Elena G. de White, Desde el Corazón [Florida, Buenos Aires: ACES, 2012], 292).

${ }^{11}$ Michael Barnes Norton, "An Interview with E. P. Sanders: 'Paul, Context, \& Interpretation", Journal of Philosophy and Scripture 2:2 (spring 2005) 37-42.

${ }^{12}$ Nacido en 1939, dos años menor que Sanders, Dunn es un líder británico erudito en Nuevo Testamento que fue por muchos años profesor de Divinidad en el Departamento de Teología de la Universidd de Durham. Después de su jubilación, fue considerado profesor emérito. Trabajó dentro de la tradición protestante. Dunn está asociado especialmente con la Nueva Perspectiva Paulina junto con los eruditos en Nuevo Testamento N. T. Wright y E. P. Sanders. Se considera que en 1982 fue el responsable de acuñar la frase "Nueva Perspectiva Paulina" en una ponencia dada en 1982 en el Manson Memorial. Otras obras de Sanders son: The Tendencies of the Synoptic Tradition (Cambridge: University Press, 1969); Paul and Palestinian Judaism (Norwich, UK: SCM Press 1977); Paul, the Law, and the Jewish People (Augsburg: Fortress Publishers, 1983); Jesus and Judaism (Norwich, UK: SCM Press, 1985); E. P. Sanders y Margaret Davies, Studying the Synoptic Gospels (Norwich, UK: SCM Press, 1989); E. P. Sanders, Jewish Law from Jesus to the Mishnah (Norwich, UK: SCM Press, 1990); Paul (Oxford: Paperbacks 1991); Judaism: Practice and Belief (Norwich, UK: SCM Press, 1992); The Historical Figure of Jesus (Penguin Books Ltd, 1993; Paul: A Very Short Introduction (Oxford: Paperbacks, 2001); "Jesus' Galilee, Fair Play: 
de Sanders fue Jesus and Judaism, publicado en 1985. En esta obra su argumento fue que Jesús comenzó como seguidor de Juan el Bautista y que fue un profeta de la restauración de Israel. Sanders vio a Jesús como creador de un movimiento judío escatológico debido a la selección de los apóstoles, y también por sus prédicas y acciones. Después de la ejecución de Cristo, detonado por la limpieza de las mesas en el Templo de Herodes y poniéndose en antagonismo con las autoridades políticas, sus seguidores continuaron el movimiento, esperando su retorno para restaurar Israel. Una consecuencia de este retorno es que involucrará a los gentiles adorando al Dios de Israel. Sanders no encontró diferencias significativas de oposición entre Jesús y los fariseos, y vio a Jesús como seguidor de las leyes judías y a sus discípulos como continuadores de esta observancia (Mt 23:2-3; Hch 3:1; 21:23-26, al adorar en el Templo). Sanders también argumenta que los dichos de Jesús no determinaron el comportamiento y actitudes del cristianismo primigenio, como está demostrado por la dis-

Diversity and Conflicts in Early Christianity". En Essays in Honor of Heikki Räisänen, eds. Ismo Dunderberg, Kari Syreeni, Christopher Tuckett, pp. 3-41 (Leiden: Brill 2001); “Jesus' Relation to Sepphoris, Sepphoris in Galilee”, en Crosscurrents of Culture, eds. Rebecca Martin Nagy, Eric M. Meyers, Carol L. Meyers, and Zeev Weiss, 75-79 (Raleigh: North Carolina Museum of Art, 1996); "Patterns of Religion in Paul and Rabbinic Judaism: A Holistic Method of Comparison", Harvard Theological Review 66 (1973) 455-78; "The Covenant as a Soteriological Category and the Nature of Salvation in Palestinian and Hellenistic Judaism," en Jews, Greeks and Christians, eds. Robert Hamerton Kelly and Robin Scroggs (Leiden: Brill, 1976), 1144; "On the Question of Fulfilling the Law in Paul and Rabbinic Judaism", en DonumGentilicum: New Testament Studies in Honour of David Daube, eds. C. K. Barrett, E. Bammel and W. D. Davies, 103-126 (Oxford: Clarendon, 1978); "Paul's Attitude Toward the Jewish People", Union Seminary Quarterly Review 33 (1978) 175-187. 
cusión de Pablo sobre el divorcio (1 Co 7:10-16) donde éste cita los dichos de Jesús y luego presenta su propia regla independiente. En una entrevista, Sanders dijo que consideraba a Pablo "el modelo de sus iglesias". ${ }^{13}$

En 1992, Sanders publicó Judaism: Practice and Belief, y probó su tesis a la luz de prácticas judías concretas. Sanders argumentó que había un "judaísmo común"; es decir, creencias y prácticas comunes a todos los judíos, sin importar a qué partido religioso adhiriera. Después del reinado de Salomé Alexandra, los fariseos eran un partido pequeño pero muy respetado y tuvo una influencia importante dentro del judaísmo. La fuente principal de autoridad, estaba en los gobernantes y especialmente en la aristocracia sacerdotal (Saduceos). Sanders presentó como argumento que la evidencia indica que los fariseos no dictaban las normas para ninguno de estos grupos o individuos. ${ }^{14}$

En general, Sanders abogó por el contexto histórico como importante para una comprensión apropiada de la religión del primer siglo. Intentó dar una idea aproximada del judaísmo, basado en sus propios términos y estudios, y no en el contexto de los debates católicos-protestantes del siglo XVI para deducir los puntos de vista sobre el judaísmo, sobre Pablo y sobre el cristianismo en general. Como el mismo Sanders lo expresa, él lee a Pablo en su propio contexto que es de la Palestina del primer siglo y especialmente del judaísmo del primer siglo. Con esto en

\footnotetext{
${ }^{13}$ Barnes Norton, “An Interview with E. P. Sanders: 'Paul, Context, \& Interpretation".

${ }^{14}$ Véase al respecto el estudio de David I. Brewer, Techniques and Assumptions in Jewish Exegesis before 70 CE (Tübingen: Mohr-Siebeck, 1992).
} 
mente, uno de los artículos de Sanders se titula "Jesús in Historical Context" [Jesús en el contexto histórico]. ${ }^{15}$ Sanders también argumentó que se necesitan más estudios comparativos, con exámenes más amplios entre textos del NT y otras fuentes históricas disponibles del período.

\section{Reacciones al trabajo de Sanders}

Pronto se le sumó el erudito James D. G. Dunn (obispo y teólogo anglicano), quien en 1982 calificó esta cuestión como un movimiento que denominó "Nueva Perspectiva Paulina". ${ }^{16}$ Aunque en realidad no puede considerarse un movimiento porque los eruditos propulsores no están de acuerdo en algunos puntos principales. De allí que varios perciben que no puede hablarse sólo de "una" NP. El trabajo de estos escritores de la NP provocó un gran número de estudios, discusiones y debates sobre temas relevantes. Esto ha hecho que en las últimas décadas se hayan publicado un gran número de libros y artículos tratando estas cuestiones. El obispo y téologo anglicano N. T. Wright (1948- ) escribió un gran número de obras que apuntaron a popularizar el punto de vista de la NP fuera del ámbito académico ${ }^{17}$ Es decir, que quienes popularizaron la obra de Sanders son teólogos anglicanos. ${ }^{18}$

${ }^{15}$ E. P. Sanders, "Jesus in Historical Context", Theology Today, 50 (October 1993): 449-448; doi 10.11771004057369305000309.

${ }^{16}$ James D. G. Dunn, "The New Perspective on Paul”, Bulletin of the John Rylands University Library of Manchester 65:2 (1983) 95-122.

${ }^{17}$ For example, N. T. Wright, What Saint Paul Really Said (Grand Rapids, Michigan: Eerdmans, 1997).

${ }^{18}$ Es importante recordar que el anglicanismo surge como desprendimiento 


\section{La NP está estrechamente relacionada con un gru- po de recientes eruditos interesados en estudiar la Bi- blia en el contexto de otros textos antiguos, y el uso del método socio-científico para comprender las culturas antiguas. Los eruditos afiliados al The Context Group [el grupo del contexto ${ }^{19} \mathrm{y}$ otros interesados en el área han}

del catolicismo en Inglaterra, y que la principal desavenencia fue no considerar la autoridad papal sino la del rey de Inglaterra en asuntos religiosos.

${ }^{19}$ Grupo internacional de eruditos bíblicos que mezclan la investigación bíblica con métodos científico-sociales como la antropología y la sociología. Su proyecto lo definen como "un proyecto sobre la Biblia en su contexto sociocultural". Se organizó en 1985, como el "Social Facets Seminar", liderado por John H. Elliott como presidente, y se reunion conjuntamente con The Jesus Seminar dirigido por Robert W. Funk y el Westar Institute. En 1989, quebró sus lazos con el Jesus Seminar y lo reorganizó en Portland, Oregon, como "The Context Group, A Project on the Bible in its Social and Cultural Environment". Dos publicaciones iniciales por sus miembros fundadores fueron: Bruce J. Malina, The New Testament World: Insights from Cultural Anthropology (Philadelphia: Westminster John Knox Press, 1981, ed. rev. 2001), que presentó un nuevo paradigma para los estudios bíblicos; y John H. Elliott, Home for the Homeless: A Sociological Exegesis of 1 Peter (Philadelphia: Fortress Press, 1981). La obra de Elliott, What is Social-Scientific Criticism of the Bible? (Guides to biblical scholarship, New Testament series, [Minneapolis: Fortress Press, 1993]) acuñó un nuevo término para la metodología del grupo y presentó un registro bibliográfico esencial. Otras figuras claves que publicaron sobre el tema durante las últimas décadas, los cuales llegaron a formar parte del Context Group, incluye a Dennis Duling, Philip Esler, Douglas E. Oakman, Jerome Neyrey, John J. Pilch, Richard L. Rohrbaugh, y Wolfgang Stegemann. En las raíces del método científico-social del Context Group se encuentra la creencia de que los eruditos bíblicos han adoptado presupuestos culturales occidentales para interpretar la Bilbia, un documento antiguo producido en una cultura muy diferente. La diferencia clave es que el mundo coccidental moderno es una sociedad industrial individualista, mientras que la sociedad del mundo antiguo del Mediterráneo era colectivista y agraria. La antigua sociedad Mediterránea era también una sociedad de un contexto elevado, cuyo discurso daba por hecho valores culturales compartidos. Esto contrasta con el mundo moderno occidental, que es una sociedad con un discurso de bajo perfil que tiende a ser más específico y especializado (por ejemplo a grupos particulares, subculturas, etc. De acuerdo con los eruditos del Context Group, el intérprete 
requerido la reinterpretación de varios textos bíblicos basados en sus estudios sobre el mundo antiguo.

Se puede decir resumidamente que E. P. Sanders es conocido por haber logrado un progreso en cuanto a la erudición en NT. Su área de mayor interés es el judaísmo y el cristianismo del mundo greco-romano.

\section{Revisión de los temas más discutidos}

Como ya se mencionó, el título singular de "la Nueva Perspectiva" da una impresión de unidad no justificada. Es un área de estudio en la que muchos eruditos están realizando intensamente investigaciones y revisando continuamente sus propias teorías a la luz de nueva evidencia, y que no necesariamente concuerdan entre si en algún aspecto. ${ }^{20}$

En 2003, N. T. Wright, se distanció de Sanders y Dunn, y comentó que existían casi tantas posturas de la "nueva perspectiva" como escritores exponiéndolas, y que no estaba de acuerdo con la mayoría de ellos. ${ }^{21}$

debe aprender los presupuestos culturales y valores detras del texto para poder comprenderlo correctamente. Esto involucra comprender valores tales como el honor y la vergüenza, por ejemplo, que Malina denomina "pivotal cultural values". Otros temas comunes del análisis bíblico de Context Group incluye el honor y la vergüenza, relación patrón-cliente, el "mal de ojo", el parentesco, los códigos de pureza, y las personalidades con orientación grupal/diádica.

${ }^{20}$ Véanse una bibliografía recopilada por Michael F. Bird sobre el tema: "The New Perspective on Paul: A Bibliographical Essay", The Paul Page, disponible en http://www.thepaulpage.com/the-new-perspective-on-paul-abibliographical-essay/; Internet (consultada el 7 de octubre de 2013).

${ }^{21}$ N. T. Wright, "New Perspectives on Paul", ponencia en la 10th Edinburgh Dogmatics Conference, del 25 al 28 de agosto de 2003; disponible en: http://ntwrightpage.com/Wright_New_Perspectives. htm; Internet (consultada el 12 de septiembre de 2013). 
Existen ciertas tendencias y afinidades en el movimiento, pero lo que tienen en común es la creencia que la AP (es decir, las interpretaciones luterana y reformista sobre Pablo y el judaísmo) es fundamentalmente incorrecta. Se ha propuesto entonces un título plural "las nuevas perspectivas" como más concordante con lo que realmente está sucediendo. ${ }^{22}$ Se listan a continuación algunos de los temas más discutidos.

\section{Teología meritoria: Obras de la ley}

Las cartas de Pablo contienen una cantidad importante de crítica sobre "las obras de la ley". Las interpretaciones de lo que Pablo quiso dar a entender por "obras de la ley" es la característica más sobresaliente entre las dos perspectivas. La AP interpreta la frase como refiriéndose al esfuerzo humano para hacer buenas obras con el propósito de alcanzar los estándares divinos (obras de justicia). De esta forma, presentan la siguiente inquietud ¿qué hay acerca del

\footnotetext{
${ }^{22}$ Otros trabajos sobre el tema y fuentes de consulta son: D. G. Dunn, "The New Perspective on Paul". Ponencia de 1982 en Manson Memorial Lecture en la que Dunn acuña la expresión "the new perspective on Paul". (Agregado el12/17/07). Disponible en portugués como "A Nova Perspective Sobre Paulo", trad. Edson Luis [Disponible en formato PDF]. N.T. Wright, "The Shape of Justification". Este documento contiene una respuesta elocuente a Paul Barnett y reacciona hacia las críticas más serias hechas por diferentes autores. (Actualizado el 2/7/02). También está disponible en español como "El estado de la justificación”, trad. Eva Navarro Estrada, rev. por Jonathan Navarro Estrada. En formato HTML Se encuentran más artículos y reseñas de libros en The Paul Page, disponible en http:// www.thepaulpage.com/new-perspective/; Internet (consultada el 29 de septiembre de 2013); y Catholic Perspective on Paul, disponible en http:/ / pauliscatholic.com/; Internet (consultada el 29 de setiembre de 2013).
} 
lenguaje rabínico que hace referencia a aquellos que al hacer ciertas cosas son merecedores del favor divino? Desde esta perspectiva, Pablo argumenta en contra de la idea de que los seres humanos pueden merecer la salvación de Dios por sus buenas obras (se puede notar que la NP concuerda en que no hay méritos salvíficos; la cuestión es explicar lo que Pablo está diciendo realmente).

En forma sorprente, Sanders desafía el punto de vista mayoritario sobre el significado de zekut. Este término no se refiere a obras "supererogatorias" o de "mérito", en la forma que le adscriben. ${ }^{23}$ Ya G. F. Moore había hecho su advertencia al respecto. ${ }^{24}$ A pesar de la usual comprensión problemática de zekut, Sanders argumenta que en general este punto ha sido ignorado. Cuando hay "recompensas por mérito", también aparece casi sin excepción recompensas bastante concretas en lo histórico y no son soteriológicas. ${ }^{25}$ Los eruditos de la

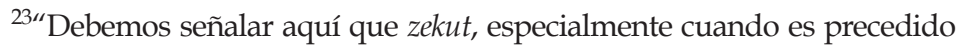
por la preposición bet (por, en), no lleva necesariamente el significado de 'mérito' en la palabra Inglés. Es decir, no se debe necesariamente suponer que la aparición de zekut siempre implica la completa doctrina de méritos almacenados que algunos eruditos han encontrado en la literatura rabínica (y en comparación con el 'tesoro de méritos' de los Católicos Romanos). Zekut sigue de cerca a la palabra en inglés 'virtud' de una manera: ambos pueden tener un significado completo o débil. Así, para decir que alguien es una persona de virtud es un importante uso de la palabra; pero en la frase 'en virtud de' el significado se debilita un poco más que 'debido a'. Uno no debe, por lo tanto, emocionarse demasiado sobre cada aspecto de la expresión bizekut - 'por virtud de' o 'por el mérito de'”. (Sanders, Paul and Palestinian Judaism, 90; para un ejemplo sobre el término zekut como teniendo ese sentido, véase la discusión de Aboth 5.18 en ibíd., 187).

${ }^{24}$ Moore, Judaism in the First Centuries of the Christian Era, 1:45.

${ }^{25}$ “Casi sin excepción la recompensa histórica es concreta y no son soteriológicas" (Sanders, Paul and Palestinian Judaism, 189). 
NP ven a Pablo definiendo el emblema que corresponde para alcanzar la membresía del pacto o, en su defecto, criticando a los creyentes gentiles que comenzaban a confiar en la Torah para ser considerados judíos. ${ }^{26}$

Fundamentalmente, la crítica de Sanders a la tradición recibida sobre el judaísmo como teología meritoria es que fue construida sobre una base metodológica falsa desde el mismo comienzo. Los reformistas ven a Pablo refutando una teología meritoria y, con este presupuesto en mente, entonces van a la Escritura para encontrar en las fuentes primarias la teología del mérito. ${ }^{27}$ Como resultado, las obras extensas escritas sobre judaísmo por los eruditos bíblicos (Weber, Schurer, Bousset) presuponen una teología del mérito antes de que se realice un examen de los textos. Esto fue advertido y corregido por Moore, pero debido a que no provocó polémica, su propia obra representó simplemente una lectura a la luz de otros. ${ }^{28}$ Sanders, por lo tanto, representa un intento por leer el judaísmo en sus propios términos para extraer un patrón religioso y de allí compararlo con el cristianismo.

${ }^{26}$ Por "insignias de la membresía de pacto" ("badges of covenant membership"), véase N. T. Wright, Paul for Everyone: Romans part one (Louisville, Philadelphia: Westminster John Knox, 2004), 35-41. Por confianza en la Torah, véase Pamela Eisenbaum, "A Remedy for Having Been Born of Woman: Jesus, Gentiles, and Genealogy in Romans", Journal of Biblical Literature 123:4 (Winter 2004) 671-702. doi:10.2307/3268465.

27“Tenemos aquí la retroyección del debate protestante-católico en la historia antigua, con el judaísmo tomando el rol del catolicismo y el cristianismo el papel del luteranismo" (Sanders, Paul and Palestinian Judaism, 57).

${ }^{28}$ Ibíd., 33-34, 58-49. 
Los argumentos incluyen discusiones acerca de cuál era la elección que estaban realmente enfrentando los israelitas en el tiempo de Pablo, si la de seguir las tradiciones ancestrales, la Torah, o seguir la tendencia del Imperio Romano de adoptar las costumbres griegas (helenización). Aquí entran en juego conceptos sobre: el antinomismo, ${ }^{29}$ el judaísmo heleno, y la controversia sobre la época del cristianismo primigenio. Es decir, habría que considerar los diferentes aspectos (sociales, culturales, lingüísticos, etc.) de la forma en la que el imperialismo afectó la cultura. ${ }^{30}$

El punto de vista de la NP es que los escritos de Pablo discuten en forma comparada los méritos de seguir el judaísmo antiguo o las costumbres griegas antiguas. Se interpreta a Pablo como crítico del punto de vista judío que circulaba en su época y que decía que las costumbres tradicionales israelitas hacían que

${ }^{29} \mathrm{El}$ antinomismo como doctrina sin movimiento afín apareció en los siglos I y II, y después esporádicamente. Generalmente se asocia al gnosticismo, al parecer, está presente también en el neognosticismo de

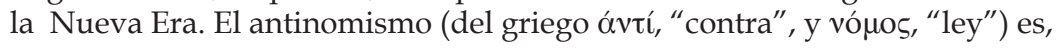
propiamente, un movimiento cristiano del siglo XVI considerado herético que defendía que la fe lo llenaba todo y era lo único necesario, y que como la ley de Moisés era inútil para la salvación, es indiferente que un creyente "persevere en pecado para que la gracia abunde" (en contradicción con Romanos 6:1-2). Esta doctrina fue propagada por su fundador Johannes Agricola, quien comenzó a desarrollar sus doctrinas en el año 1537, hallándose en Wittenberg como profesor, por lo cual a sus partidarios se les conoce también con el nombre de los reformadores de Wittenberg. Aquí fue donde tuvo controversias con Lutero y Melanchton, huyendo luego a Berlín donde escribió una retractación.

${ }^{30}$ Esto podría compararse con la occidentalización y la decisión enfrentada por los individuos modernos; por ejemplo la de los indígenas si deben seguir con su cultura nativa o adoptar las costumbres y estilos de vida occidentales. 
una persona sea considerada mejor ante Dios. Es por eso que Pablo indicó que Abrahán fue justo antes que la Torah fuera dada a Moisés. ${ }^{31}$ También se señala que Pablo identifica costumbres que ocuparon un lugar importante en su discusión epistolar como la circuncisión, las leyes dietarias y la observancia de días especiales.

\section{El esfuerzo humano: el juicio acorde a las obras}

Debido a la interpretación de la frase "obras de la ley", los teólogos de la AP ven la retórica paulina como contraria al esfuerzo humano por ganar la salvación. Luteranos y teólogos reformistas citan esto como una característica central de la religión cristiana, y los conceptos de sola gratia y sola fide son muy importantes en las creencias de estas denominaciones.

Sanders reconoce que la literatura judía del primer siglo apunta a un juicio futuro acorde con las obras. No obstante, se lo debe entender (con excepción a Esd 4) que el tema de la retribución estricta se relaciona con el tema de la misericordia de Dios. ${ }^{32}$ Es por eso, que las

${ }^{31}$ Esto es incorrecto ya que Abrahán recibió la ley antes que Moisés, la diferencia fue que no se le pidió una transmisión escrita (Gén 26:5; cf. Deu 8:11).

32“Hay dos formulaciones diferentes sobre la misericordia y la justicia. Una de ellas es el de la literatura rabínica: la misericordia de Dios es mayor que su justicia. En la otra literatura, la formulación habitual es que Dios castiga a los malos por sus actos, mientras otorga misericordia sobre los justos... Los temas de la misericordia y justa retribución no están realmente en competencia, pero sirven para diferentes funciones. Declaraciones en el sentido de que Dios le paga a cada hombre lo que debe servir para afirmar la justicia de Dios y para dar garantías tanto a los pecadores como a los justos que lo que ellos hacen, importa. Dios no es caprichoso. Él no castiga por la obediencia ni recompensa la transgresión. 
interpretaciones de la NP sobre Pablo vienen como resultado de que Pablo no tiene nada negativo que decir sobre el esfuerzo humano o las buenas obras, y dice muchas cosas positivas sobre ambos conceptos. Los eruditos en la NP presentan que muchos pasajes paulinos especifican que los criterios del juicio final están basados en las obras del individuo.

Wright dijo que Pablo tenía bien en claro que el juicio final era de acuerdo a las obras (así como Jesús). Pablo, junto con la línea principal del judaísmo del Segundo Templo, afirma que el juicio final de Dios estará en concordancia con la conducta de toda la vida y, por lo tanto, en otras palabras, de acuerdo con las obras. ${ }^{33}$

No obstante, Wright no sostiene que las buenas obras contribuyen a la propia salvación, más bien que el juicio final es algo hacia lo que se puede mirar como una futura vindicación de la declaración presente divina de la justicia del individuo. Es decir, las obras son el resultado

El tema de la misericordia - si se coloca en los términos de la misericordia de Dios en elegir a Israel, la misericordia de Dios en aceptar a los pecadores arrepentidos (el arrepentimiento no gana un premio, pero es respondido por Dios en su misericordia), o la 'recompensa' de Dios a los justos por su misericordia - sirve para asegurar que la elección y, en última instancia, la salvación no puede ser ganadas, sino que dependen de la gracia de Dios. Uno nunca puede ser lo suficientemente justo para ser digno a la vista de Dios y sus dones últimos, los que dependen sólo de su misericordia. El tema de la misericordia de Dios como siendo la confianza final aun de los justos aparece en toda la literatura examinada excepto en IV de Esdras"(Sanders, Paul and Palestinian Judaism, 421-422).

${ }^{33}$ "El juicio final de acuerdo a las obras... era bastante claro para Pablo (tal como lo era para Jesús). Pablo, en conformidad con la corriente principal del judaísmo del segundo templo, afirma que el juicio final de Dios será de acuerdo con la totalidad de una vida guiada - en otras palabras, de acuerdo con las obras" (N. T. Wright, “New Perspectives on Paul”). 
de que el individuo ha sido salvado y el juicio futuro lo demostrará. Otros colocan un valor elevado en la importancia de las buenas obras en relación a lo que lo hacía la $\mathrm{AP}$, adoptando el punto de vista de que realmente contribuyen causalmente a la salvación del individuo.

La AP acusa que esto es "salvación por obras", y como algo negativo, pues contradice doctrinas fundamentales del cristianismo. Los eruditos de la NP responden que sus puntos de vista no son tan diferentes. Porque en la $\mathrm{AP}$, Dios otorga poder por su gracia al individuo mediante la fe que conduce a la salvación y también a las buenas obras, mientras que en la NP, Dios por gracia otorga poder a los individuos para la fe y las buenas obras, que conducen a la salvación. ${ }^{34}$

\section{Fe y fidelidad}

Un debate relacionado con la NP tiene que ver con el uso que hace Pablo de la palabra griega Jíotıs (como significando "confianza", "creencia", "fe", o "fidelidad"). Los escritores de la AP la interpretaron generalmente como la creencia en Dios y Cristo, y la confianza en Cristo para salvación con la fe en que él salva. Esta interpretación está basada en varios pasajes de la Biblia, principalmente Efe 2:8-9, que dice "Porque por gracia ustedes han sido salvados mediante la fe; esto no procede de ustedes, sino que es el regalo de Dios, no por obras, para que nadie se jacte". El mismo E. P. Sanders nota que Efe 2:9 enseña la tradicional AP. ${ }^{35}$

${ }^{34}$ Ver conceptos de sinergía en la teosis de la Iglesia Ortodoxa Oriental y la Ortopraxis en el cristianismo.

${ }^{35}$ Guy Prentiss Waters indica que "Sanders me ha confirmado que 
En contraste con esto, estudios recientes sobre la

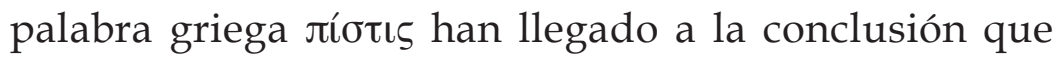
su significado primario y más común era fidelidad, a saber, un firme compromiso en una relación interpersonal. ${ }^{36}$ Como tal, la palabra podría ser casi sinónimo de "obediencia" cuando los involucrados en la relación sostienen estatus de niveles diferentes (por ejemplo, un esclavo que es fiel a su amo). Esto está lejos de ser el equivalente de "carencia de esfuerzo humano", la palabra parece implicar y requerir el esfuerzo humano. La interpretación en los escritos de Pablo de que se necesita una obediencia fiel a los mandamientos de Dios es bastante diferente de la que considera que él dice que se necesita tener " $\mathrm{fe}$ " y que Dios hará todo por uno. Esto también explica la relación de Pablo con la epístola de Santiago, que Lutero casi borró del canon bíblico porque dice que "la fe sin obras es muerta" y que un hombre "se salva por obras y no sólo por fe", y agrega que sólo creer lo coloca a uno en igual condición que un demonio (Sant 2). La NP argumenta que Santiago estaba interesado en tratar con aquellos que procuraban reducir la fe a una cuestión intelectual sin ninguna intención de seguir a Dios o Jesús, y que Pablo consideró la fe como una completa sumisión a Dios.

Efesios 2: 9 enseña la visión tradicional" (Justification and the New Perspectives on Paul [New Jersey: P \& R Publishing, 2004], 167).

${ }^{36}$ Douglas A. Campbell, The Quest For Paul's Gospel: A Suggested Strategy (Bloomsbury: T\&T Clark, 2005), 178-207; D. M. Hay, "Pistis as "Ground for Faith" in Hellenized Judaism and Paul", Journal of Biblical Literature 108:3 (1989) 461-476; G. Howard, "The 'Faith of Christ'”, The Expository Times 85:7 (1974) 212-215; John J. Pilch y Bruce J. Malina, eds., Handbook of Biblical Social Values (Peabody, Massachusetts: Hendrikson, 1998), 72-75. 
Otra cuestión en cuanto a este tema está relaciona-

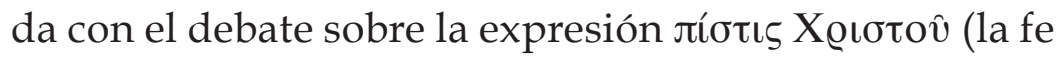
de Cristo). Varias veces Pablo usa esta frase en cuestiones clave en sus escritos y es lingüísticamente ambigua pues no se sabe si se refiere a la fe en Cristo (genitivo de objeto), o la propia fidelidad de Cristo a Dios (genitivo de sujeto), o incluso la fe/fidelidad del individuo a Dios como la que tuvo Cristo (genitivo adjetivo). Hay gran desacuerdo con la comunidad académica sobre cuál de estas interpretaciones es la que mejor representa lo que dijo Pablo. ${ }^{37}$ La nueva traducción en inglés de la Biblia (NET) fue la primera traducción que interpretó esta frase como genitivo de sujeto, ${ }^{38}$ es decir, como la fidelidad de Cristo a Dios.

\section{Gracia o favor}

Otro tema debatido es si hay que interpretar el tér-

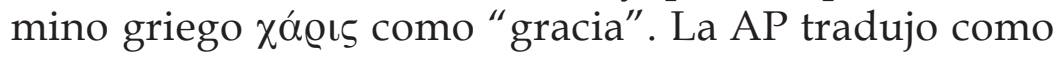

${ }^{37}$ Ver, por ejemplo, para genitivo de sujeto: G. Howard, “The 'Faith of Christ'", The Expository Times 85:7 (1974) 212-215; Richard B. Hays, The Faith of Jesus Christ: The Narrative Substructure of Galatians 3:1-4:11, vol. 56 de Biblical Resourse Series (Grand Rapids, Michigan: Eerdmans, 2002);

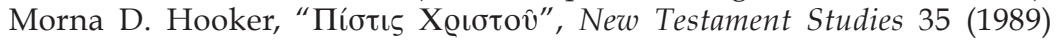
321-342. Para genitivo de objeto: A. J. Hultgren, "The Pistis Christou Formulation in Paul", Novum Testamentum 22:3 (1980) 248-263; J. D.

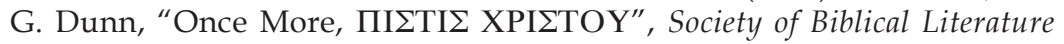
Seminar Papers (1991): 730-744.

${ }^{38}$ Por ejemplo, Rom 3:21-22: "Pero ahora, aparte de la Ley, se ha manifestado la justicia de Dios, testificada por la Ley y por los Profetas: la justicia de Dios por medio de la fe en Jesucristo, para todos los que creen en él, porque no hay diferencia..."; y Gál 2:20: Con Cristo estoy juntamente crucificado, y ya no vivo yo, mas vive Cristo en mí; y lo que ahora vivo en la carne, lo vivo en la fe del Hijo de Dios, el cual me amó y se entregó a sí mismo por mí". 
refiríendose a la idea de que hay carencia de esfuerzo humano en la salvación porque Dios es el factor controlador. No obstante, quienes estudian la cultura griega antigua señalan que "favor" es una mejor traducción, porque la palabra normalmente se refiere a "hacer un favor". En las sociedades antiguas existía la expectativa que esos favores se devolvieran, y este sistema semi-formal de favores funcionaba como préstamos. ${ }^{39}$ Por lo tanto, se argumenta que cuando Pablo habla de cómo Dios hizo un "favor" a la humanidad al enviar a Jesús, está diciendo que Dios tomó la iniciativa, pero no está implicando una falta de esfuerzo humano en la salvación, sino que está implicando que los cristianos tienen una obligación de devolver el favor que Dios les ha hecho. Algunos argumentan que este punto de vista desmerece el "favor" inicial -de enviar a Jesús- al decir que, a pesar de su encarnación, vida y muerte, los cristianos todavía tienen, como antes que ganar su camino al cielo. No obstante, otros notan que son las salientes de un falso dilema o dicotomía (toda gracia vs. todo obras). Varios proponentes de la NP que ven el término

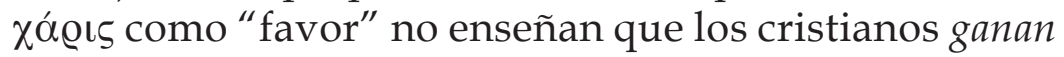
su pasaje al cielo sin la muerte de Cristo. El perdón de los pecados mediante la sangre de Cristo es necesario para la salvación. Pero, el perdón demanda un esfuerzo de parte del individuo (Fil 3:12-16). ${ }^{40}$

\footnotetext{
${ }^{39}$ David A.de Silva, Honor, Patronage, Kinship and Purity: Unlocking New Testament Culture (Downers Grove, Illinois: Intervarsity Press, 2000), 117.

${ }^{40}$ N. T. Wright, "Romans and the Theology of Paul", en Pauline Theology, Vol. III, eds. David M. Hay y E. Elizabeth Johnson, 30-67 (Minneapolis: Fortress Press, 1995).
} 


\title{
La expiación
}

\section{Otro tema: el concepto sobre "expiación". Para los escritores de la AP, la teoría de expiación de la "subs- titución penal" ${ }^{41}$ y la creencia en la "obra terminada"}

\begin{abstract}
${ }^{41} \mathrm{~A}$ veces se la denomina, especialmente en los antiguos escritos, "teoría forense" (David Smith, The Atonement in the Light of History and the Modern Spirit [London: Hodder and Stoughton, 1918. Reimpresión por BiblioBazaar, 2010], 96-97). Es una teoría sobre la expiación dentro de la teología cristiana, desarrollado con tradición reformista (Vincent Taylor, The Cross of Christ [London: Macmillan \& Co, 1956], 71-72: “...los cuatro tipos principales, que han persistido a lo largo de los siglos. La teoría más antigua es la Teoría de Ransom... Esta dominó durante mil años. [...] La Teoría forense es la de los reformadores y sus sucesores". J. I. Packer, What did the Cross Achieve? The Logic of Penal Substitution [Tyndale Biblical Theology Lecture, 1973]: “...Lutero, Calvino, Zwinglio, Melanchton y sus contemporáneos de la Reforma fueron los pioneros en afirmar esto [es decir, la teoría sustitutiva penal]...). Esta teoría argumenta que Cristo, por su propia elección de sacrificio, fue castigado en lugar de los pecadores (sustitución). Así satisfizo las demandas de la justificación para que Dios pudiera otorgar perdón de pecados justamente. Es, por lo tanto, una comprensión específica de la expiación sustitutiva donde la naturaleza sustitutoria de la muerte de Jesús se entiende en el sentido de "castigo sustitutorio". La sustitución penal deriva de la idea de que el perdón divino debe satisfacer la justicia divina; es decir, que Dios no está dispuesto o tiene capacidad de simplemente perdonar el pecado sin primero requerir una satisfacción por él. Declara que Dios se dio a sí mismo en la persona de su Hijo, Jesucristo, para sufrir la muerte, el castigo y la maldición que correspondían a la humanidad caída como penalidad por sus pecados. Esta teoría fue condenada como "Patripasianismo" y el "Teopasionismo", como fue enseñado por Sabellius porque requiere que el Padre sufra igualmente con el Hijo pues la Trinidad es Dios. Esta unidad de Dios en el "Homoousion" (acuñada por Sabellius) requirió que la Trinidad sea comprendida por lo que se denominó la herejía del "Modalismo" (es una creencia no trinitaria de que el Padre Celestial, el Hijo Resucitado y el Espíritu Santo son modos o aspectos diferentes de un Dios monádico, como es percibido por el creyente, en lugar de tres personas distintas en la Divinidad). Mientras que la sustitución penal comparte estos temas presentes en muchas otras teorías de la expiación, la sustitución penal es una comprensión distintiva del protestantismo sobre la expiación que difiere de la Católica Romana o la Ortodoxa Oriental. Varios trazan su origen
\end{abstract}


de Cristo ha sido central. Los escritores de la NP han cuestionado en forma regular si este punto de vista es realmente de importancia central en los escritos paulinos. Generalmente, los escritores de la NP argumentan que otras teorías de la expiación son más centrales al pensamiento de Pablo, pero hay poco acuerdo entre ellos sobre cuál es realmente el punto de vista real de Pablo sobre la expiación.

Algunos ejemplos de los diferentes puntos de vista son:

1. E. P. Sanders argumentó que la idea central de Pablo era que los creyentes participaban en forma mística y espiritual en el Cristo resucitado, y que la terminología judicial está subordinada a la participacionista. ${ }^{42}$

2. N. T. Wright argumentó que Pablo ve a Israel como representante de la humanidad y cargando sobre sí la pecaminosidad de la humanidad a lo largo de la historia. Jesús, en cambio, como Mesías es representante de Israel y colocó los pecados de Israel sobre sí mismo en la cruz. El punto de vista de Wright es una forma "histórica" de la sustitución penal. ${ }^{43}$

3. Chris Van Landingham argumentó que Pablo ve a Cristo como vencedor del Demonio y enseñando a los

en Calvino, pero fue concretamente formulado por Charles Hodge (pastor presbiteriano, 1797-1878). Tradicionalmente la creencia en una sustitución penal se ha considerado la marca de la fe evangélica, y esta incluida en un artículo de fe en varias organizaciones evangelicas actualmente.

${ }^{42}$ Sanders, Paul and Palestinian Judaism: A Comparison of Patterns of Religion.

${ }^{43}$ N. T. Wright, Jesus and the Victory of God (Minneapolis: Fortress Press, 1996). 
seres humanos cómo Dios desea que vivan y les pone un ejemplo. ${ }^{44}$

4. David Brondos argumentó que Pablo ve a Jesús como solamente una parte en una narrativa más amplia en la cual la Iglesia está operando para transformar las vidas de los individuos y el mundo, y que la terminología participatoria paulina debiera comprenderse en un sentido ético (seres humanos viviendo vidas como la de Cristo) en lugar de místicamente como lo expresa Sanders. ${ }^{45}$

5. Pilch y Malina asumen la postura de que Pablo apoya la teoría de la expiación de satisfacción o restitución. ${ }^{46}$

6. Stephen Finlan sostiene que Pablo usa numerosas metáforas diferentes para describir la expiación; "justificados por su sangre" (Rom 5:9) significa que una sustancia cúltica tiene un efecto judicial. Pablo también enseñó la transformación de los creyentes a la imagen de Dios mediante Cristo (Teosis o divinización de la materia por la eliminación del pecado). ${ }^{47}$

${ }^{44}$ Chris VanLandingham, Judgment and Justification in Early Judaism and the Apostle Paul (Peabody, Massachusetts: Hendrickson, 2006), 100, 107, $191,327$.

${ }^{45}$ David Brondos, Paul on the Cross: Reconstructing the Apostle's Story of Redemption (Van Gorcum; Minneapolis: Fortress Press, 2006), 67, $112,151$.

${ }^{46}$ Bruce J. Malina y John J. Pilch, Social-Science Commentary on the Letters of Paul (Peabody, Massachusetts: Fortress Press, 2006).

${ }^{47}$ Stephen Finlan, Problems with Atonement: The Origins of, and Controversy about, the Atonement Doctrine (Collegeville, MN: Liturgical Press, 2005), 58-59, 120-123. 


\section{Reacciones a la Nueva Perspectiva}

Como se puede apreciar, la discusión sigue en desarrollo. Uno de los téologos influyentes que ha reaccionado a este debate y que está teniendo influencia importante actualmente es Simon Gathercole. Su tesis propone una revisión de los puntos de vista de NP en relación con los presupuestos paulinos basado en su estudio del término "jactancia" en Rom 1 al 5. Pero esto no es todo. La NP ha sido un tema extremadamente controvertido y que ha provocado fuertes debates y recriminaciones desde diferentes ángulos.

¿Cómo se debe evaluar la obra de Sanders? Esta pregunta aún permanece sin respuesta, y sería imprudente que alguien que no es experto en la literatura judía pretenda simplemente aceptarla o rechazarla sobre otra base que no sea la de sus propios escritos. ${ }^{48}$ Hay algunas cuestiones que debieran tenerse en cuenta en esta discusión:

1. El punto de Sanders tiene que verse a la luz de sus presupuestos. Así como él cuestionó los presupuestos con los que los protestantes revisaron los escritos judíos, de la misma forma, se debe revisar cuál fue su presupuesto para realizar la revisión. Si su interés primario para investigar la literatura judía fue exonerar al judaísmo del perjudicial presupuesto protestante, entonces tuvo una tremenda presión

${ }^{48}$ Por ejemplo: se puede juzgar un libro, por la propia evidencia que contiene. Cuando un autor cita un pasaje, ¿siguen sus comentarios el significado aparente del texto? ¿Siguen las conclusiones el argumento que se fue acumulando? 
para validarlo. En este contexto, es difícil hacerse la pregunta correcta sobre la literatura judía. ${ }^{4}{ }^{9}$

2. Es importante reconocer que los puntos de vista extremos respecto del judaísmo fueron filtrados por dos lentes que pueden haber estado seriamente distorsionadas: (a) las luchas de los reformadores contra el legalismo de la teología escolástica medieval del catolicismo romano; (b) el producto de la erudición fuertemente centrada en el anti-semitismo de la erudición alemana del siglo XIX. Si estas dos cuestiones se encuentran presentes en un erudito, es difícil que vea las distorsiones que siguen. Además subyace una fuerte tendencia ecuménica en los presupuestos de varios eruditos.

3. Sanders mismo distorciona el cuerpo de la evidencia al rechazar tratar con el NT como testigo del judaísmo del primer siglo. Para Sanders el NT no debe ser admitido como testigo, porque es "polémico" y, por lo tanto, una guía insegura..$^{50}$ Ésta es una de las razones que se deben enfrentar al tratar con eruditos críticos que no son creyentes. ${ }^{51}$

4. Con lo dicho en los puntos anteriores, es importante que los eruditos protestantes reconozcan que el pro-

${ }^{49}$ Esto se asemeja a la discusión de Sanders con la obra de David Flusser, que hizo el mismo trabajo pero en la dirección opuesta al examinar los escritos de Qumrán. No es de sorprenderse que resultara en un punto de vista que distorsiona tremendamente el cristianismo (Sanders, Paul and Palestinian Judaism, 15-16).

${ }^{50}$ Ibíd., 152, nota 23.

${ }^{51}$ Para tener una idea de la fe de Sanders, ver su comentario crítico sobre la "verdad" en Barnes Norton, "An Interview with E. P. Sanders 'Paul, Context, \& Interpretation'", 39. 
blema del rechazo no comienza con el estudio de los textos del judaísmo, sino con las mismas Escrituras. Es posible que se le imponga los problemas de la era de la Reforma a la literatura del judaísmo. También es posible que se impongan sobre la misma Escritura. En un contexto religioso (la teología escolática del catolicismo romano) donde la "ley" fue quitada de su contexto histórico para convertirla en un "principio meritorio", es muy fácil presuponer ese significado cuando se lee de "nomos" en el NT. Igualmente, cuando rivales en una polémica están promoviendo la salvación por vía meritoria, es fácil inconscientemente ver vendedores de méritos entre los adversarios de Jesús y Pablo. Es necesario preguntarse, en forma separada de la evidencia extrabíblica, si se puede releer todos esos textos con una luz diferente; si la crítica de los judaizantes o judíos no cristianos pueden tener un mejor sentido sin presuponer una teología de mérito ominipresente.

5. Como el mismo Sanders lo previó, el intento por trata con todo el judaísmo del Segunto Templo en forma unificada, y determinar un solo "patrón religioso", es en sí un emprendimiento cuestionable. Como se ha dicho reiteradamente, es más seguro hablar de judaísmos (en plural) que de una entidad monolítica que nunca existió..$^{52}$ El significado de esta disparidad, no obstante, no debiera exagerarse.

6. La lectura que hace Sanders mismo de los escritos paulinos ha sido cuestionada por otros eruditos

${ }^{52}$ Véase al respecto Brewer, Techniques and Assumptions in Jewish Exegesis before 70 CE. 
que se consideran dentro de la NP. Sanders parece manejar poca competencia teológica respecto de los escritos paulinos. ${ }^{53}$

7. Por último, no es necesario considerar que la denominada NP, en toda su amplitud, debiera identificarse con Sanders. No todo lo que él dice encuentra aceptación en otros eruditos. Pocos eruditos bíblicos han seguido a Sanders en sus exégesis de Pablo, la mayoría de ellos están en abierta oposición con él. Por lo tanto, no existe tal cosa como una Nueva Perspectiva sobre Pablo, más bien hay un gran número de eruditos bíblicos que intentan darle sentido a Pablo a la luz de los nuevos estudios sobre el judaísmo. Varios eruditos adheridos a la NP han corregido y modificado algunas propuestas de Sanders. ${ }^{54}$

\section{Criticismo y retórica}

En 2003, Steve Chalke, influenciado por escritores de la NP, publicó un libro que tenia como objetivo el público en general y que hacía comentarios altamente críticos sobre la teoría de la sustitución penal de la expiación..$^{55}$ Esto causó un intercambio extenso y todavía en proceso entre los evangélicos de Inglaterra, con una reacción

${ }^{53}$ Por ejemplo, su aparente presuposición de que los temas sobre substitución y participación son mutuamente excluyentes (Sanders, Paul and Palestinian Judaism, 463-468).

${ }^{54}$ Véase la variedad de propuestas y conclusiones del compendio en dos volúmenes de los editores D. A. Carson, Peter T. O'Brien y Mark A. Seifrid, Justificacion and Variegated Nomism (Grand Rapids, Michigan: Baker, 2001, 2005), así como las críticas al mismo.

${ }^{55}$ Steve Chalke y Alan Mann, The Lost Message of Jesus (Grand Rapids, Michigan: Zondervan, 2003). 
negativa de parte de los laicos y los defensores de las tradiciones luterana y reformista.

Ambos lados en el debate intentan proclamar el punto de vista más elevado y confiable de la Escritura. Los defensores de la NP expresan que los que sostienen la $\mathrm{AP}$ están demasiado comprometidos con la tradición histórica protestante, $y$, por lo tanto, no pueden realizar una lectura "natural" de la Biblia; mientras que los de la AP dicen que los defensores de la NP son muy intrigantes al interpretar ciertos contextos de la historia, que entonces conducen a enfoques hermenéuticos tendenciosos hacia el texto.

Phil Johnson hizo una acusación importante cuando afirmó que no es posible considerar que Sanders y quienes concuerdan con él son los primeros en entender correctamente las Escrituras debido a que Sanders mismo cuestiona la mayoría de las epístolas de Pablo. ${ }^{56}$

Otra de las críticas o acusaciones hechas a la NP por eruditos conservadores de la tradición reformista, es que menoscaba la interpretación agustiniana clásica e individualista de la elección y que no refleja fielmente las enseñanzas de las Escrituras. Esto ha sido objeto de un reñido debate entre los evangélicos en años recientes, mayormente debido a la popularidad creciente de N. T. Wright entre los círculos evangélicos. Los críticos más ásperos incluyen calvinistas como John Piper, ${ }^{57}$ Sinclair

${ }^{56}$ Phil Johnson, “A Velha Perspectiva Sobre Paulo: Uma Introdução Crítica de 'O Que Sao Paulo Realmente Disse'”, en Ouro de Tolo? Discernindo a Verdade em uma época de erro, ed. John Macarthur, trad. Mauricio Fonseca dos Santos Junior, 63-82 (San Pablo, Brasil: Editora Fiel, 2006), 70, 7; disponible en http://www.vivendopelapalavra.com/download/Ouro_ de_Tolo.pdf; Internet (consultada el 7 de octubre de 2013).

${ }^{57}$ John Piper, Entrevista con Piper sobre Wright, October 11, 2007, 
Ferguson, ${ }^{58}$ C. W. Powell,${ }^{59}$ Mark Seifrid, D. A. Carson, ${ }^{60}$ Tom Holland, ${ }^{61}$ Ligon Duncan. ${ }^{62}$ Por ejemplo, Barry D. Smith expresó que el desafío de la NP al punto de vista tradicional, que describe la práctica de la fe judía como legalista, está desubicado. ${ }^{63}$

\section{Reacciones católicas y ortodoxas}

En forma similar a la respuesta de parte de teólogos anglicanos, los escritores de las iglesias Católica Romana y Ortodoxa Oriental, por lo general, han res-

disponible en http://www. desiringgod.org/resource-library/interviews/ interview-with-john-piper-about-the-future-of-justification-a-response-ton-t-wright; Internet (consultada el 16 de septiembre de 2013).

${ }^{58}$ Sinclair Ferguson, "What Does Justification Have to do with the Gospel?"; Ligon Duncan y Sinclair Ferguson (video resource) "Is Wright Teaching Another Gospel?".

${ }^{59}$ C. W. Powell, "Was There Legalism in First Century Judaism", disponible en: http://basketoffigs. org/NewPerspectives/Jewlegalism. htm; Internet (consultada el 7 de septiembre de 2013).

${ }^{60}$ D. A. Carson, “The New Perspective on Paul", Theology Network, disponible en http://www.theologynetwork.org /christian-beliefs/ justification/; Internet (consultada el 7 de octubre de 2013).

${ }^{61}$ Tom Holland, Contours of Pauline Theology (Fern, Scotland: Mentor, 2004). Disponible también en: http://www.tomholland.org.uk/contoursof-pauline-theology/; Internet (consultada el 7 de septiembre de 2013).

${ }^{62}$ J. Ligon Duncan, "The Attractions of the New Perspective(s) on Paul". Ponencia presentada en Jackson, Mississippi. Disponible en http://www. alliancenet.org/partner/Article_Display_Page/0,_PTID307086_CHID560462_ CIID1660662,00.html; Internet (consultada el 7 de septiembre de 2013).

${ }^{63}$ Barry D. Smith, The Tension Between God as Righteous Judge and as Merciful in Early Judaism (Lanham: University Press of America, 2005); idem, What Must I Do to Be Saved? Paul Parts Company with His Jewish Heritage (Sheffield: Sheffield Phoenix, 2007). 
pondido favorablemente a las ideas de la NP. Ambas vieron aspectos comunes con sus propias creencias y observaron fuertes similitudes con los puntos de vista de varios de los Padres de la Iglesia tempranos. Desde el punto de vista católico, la NP es vista como un escalón hacia la realidad progresiva de la salvación humana en Cristo. Más aún, los pasajes en las obras de varios de los Padres de Iglesia tempranos muestran que sostenían ampliamente los estilos de interpretación de la NP. ${ }^{64}$

Una de varias excepciones es Agustín de Hipona. Mientras que la mayoría de las escuelas católicas romanas y ortodoxas orientales considerarían que expone un punto de vista de la gracia y justificación en relación con esta nueva perspectiva, Agustín es considerado blasfemo por algunos debido a que introdujo ideas incorrectas (algunos ortodoxos concordarían que le erró al exponer estas ideas e introdujo fantasías en las enseñanzas de los padres de la iglesia). ${ }^{65}$

La importancia creciente que los escritores de la NP han dado a las buenas obras en la salvación ha

${ }^{64}$ Ireneo, "Against Heresy" 4:13-16; Ambrosiaster, "Commentary on Romans"; Pelagio, "Commentary on Romans"; Orígenees "Commentary on Romans"; Justino Martir, "Dialogue" Cap 10-11; Clemente of Alejandria, "Stromata" 6:6; Ignacio, "Magnesians" 8; Cirilo de Jerusalem, "Catechetical Lectures", 4:33. Los católicos tienen varias contribuciones en el area de los estudios rabínicos en las escuelas españolas y francesas. Por ejemplo, se pueden ver las obras de Joseph Bonsirven (1880-1958) un teólogo bíblico y católico, cuya tesis doctoral se tituló "Eschatologie rabbinique d'après les targums, talmuds, midrashs. Les éléments communs avec le Nouveau Testament" (1910), y otras contribuciones sobre el judaísmo y los escritos bíblicos. Uno importante en esta discusión es Exégese Rabbinique et Exégese Paulienne (Paris: Beauchesne, 1939).

${ }^{65}$ Fr. John Romanides, The Ancestral Sin (New Jersey, NJ: Zephyr Publishing, Ridgewood, 1998). 
creado fuertes terrenos en común con las iglesias Católica Romana y Ortodoxa Oriental. El protestantismo histórico nunca ha negado que hay un lugar para las obras buenas y fieles, pero siempre las ha excluido de la justificación y salvación. Los protestantes discuten que la salvación es sólo mediante la fe, y que las buenas obras no se toman en cuenta, tanto se esté dentro como fuera de la gracia de Dios. ${ }^{66}$ Esta cuestión ha sido una línea que distinguió, desde la Reforma, el protestantis-

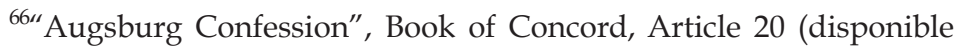
en: http:/ / bookofconcord.org/ augsburgconfession.php\#article20; Internet (consultada el 15 de septiembre de 2013) “[...] Además, nosotros enseñamos que es necesario hacer buenas obras, que no debemos confiar en ellas para merecer la gracia, sino porque es la voluntad de Dios. Es sólo por la fe, a cambio de nada que es recibido el perdón de los pecados. Y debido a que por la fe se recibe el Espíritu Santo, los corazones son renovados y dotados con nuevos afectos, de modo que sean capaces de producir buenas obras. Ambrosio dice: la fe es la madre de una buena voluntad y el bien hacer. Los poderes del hombre sin el Espíritu Santo están llenos de afectos impíos, y son demasiado débiles para hacer obras que son buenas a los ojos de Dios. Además, ellos están en el poder del demonio que impulsa a los hombres a diversos pecados, a opiniones impías, para abrir los crímenes. Esto se puede ver en los filósofos, que, a pesar de que trataban de vivir una vida honesta, no tenían éxito, pero se contaminaron con muchos crímenes abiertos. Tal es la debilidad del hombre cuando está sin fe y sin el Espíritu Santo, y se gobierna a sí mismo sólo por la fuerza humana. Por lo tanto, se puede ver fácilmente que esta doctrina no debe ser acusada de prohibir las buenas obras, sino más bien ser del más digno de elogio, porque muestra cómo somos capaces de hacer buenas obras. [...]". Véase también John Calvin, Commentary on James, Commentary on the Catholic Epistles, James 2:18-19, (disponible en: http://www.ccel.org/ ccel/calvin/calcom45.vi.iii.vi.html; Internet [consultada el 15 de septiembre de 2013]) “[...] Esto sólo quiere decir, que la fe, sin la evidencia de las buenas obras, es una pretensión vana, porque la fruta siempre viene de la raíz viva de un buen árbol.[...]”.
} 
mo Luterano ${ }^{67}$ y Reformista ${ }^{68}$ de otras denominaciones cristianas.

En definitiva, la NP propone reconocer que el judaísmo no es una religión en la cual las personas logran autojustificarse ante Dios. El argumento paulino con los judaizantes no era acerca de la gracia de Cristo vs. el legalismo judío. Su argumento era más bien acerca del estatus de los gentiles en la iglesia. La doctrina de la justificación, por lo tanto, tiene más que ver con cuestiones entre judíos y gentiles que con cuestiones del estatus del individuo ante Dios. Esto desde ya desafía los antecedentes sobre las interpretaciones de la misma discusión que establece Pablo en Romanos.

67"Augsburg Confession”, Book of Concord, Article XII: “Ellos también son rechazados por no enseñar que la remisión de los pecados viene por la fe, en cambio nos ordenan a merecer la gracia a través de las satisfacciones de nosotros mismos."

${ }^{68}$ "Canons of Dort", Encabezado 1, par 3 (disponible en http:// www.spurgeon.org/ phil/creeds/dort.htm; Internet [consultada el 15 de septiembre de 2013]) "Rechazo de errores[..] [de los q]ue enseñan: Que la buena voluntad y el propósito de Dios, de la cual la Escritura hace mención en la doctrina de la elección, no consiste en esto, que Dios escogió a ciertas personas antes que a otros, pero en esto, que Él eligió de todas las condiciones posibles (entre las que destacan también las obras de la ley), o fuera de todo el orden de las cosas, que el acto de fe que por su misma naturaleza es inmerecido, así como la obediencia incompleta, como una condición para la salvación, y que Él amablemente consideró esto en sí mismo como una obediencia completa y lo cuenta como digno de la recompensa de la vida eterna. Porque por este error perjudicial la satisfacción de Dios y los méritos de Cristo se hacen sin efecto, y los hombres son alejados por cuestiones inútiles de la verdad de la justificación gratuita y de la sencillez de la Escritura, y esta declaración del apóstol se considera como falsa: "Quien nos salvó y llamó con llamamiento santo, no conforme a nuestras obras, sino según el propósito suyo y la gracia que nos fue dada en Cristo Jesús antes de los tiempos de los siglos (2 Tim 1:9)". 
Los que favorecen la NP prometen ayudar en:

1. Comprender mejor a Pablo y la iglesia primitiva.

2. Reconciliar a los eruditos bíblicos con la teología.

3. Construir un terreno común entre los católicos y los protestantes.

4. Mejorar el diálogo entre cristianos y judíos.

5. Dar cuerpo al fundamento teológico por la justicia social.

\section{Posible inclusión en el diálogo de los adventistas del séptimo día}

Algunos consideran que es interesante notar la compatibilidad que existe entre la NP y los adventistas en nociones como la ley, la gracia, la fe y las obras. Esta situación llevó en el pasado, al igual que en el presente, a calificar a quienes hacían énfasis en la vigencia de la ley fueran considerados legalistas. En el pasado, el énfasis de la Iglesia Adventista (IASD) sobre la vigencia de la ley, especialmente del sábado, y la fuerte interpretación escatológica basada en los conceptos del santuario judío en el AT, hizo que se la considerara como legalista y con un concepto soteriológico errado en relación con la herencia protestante.

La IASD ha argumentado con pasajes como Gál $3: 7,16,28,29$; que uno no es salvado en virtud de ser judío (teniendo la ley/Torah/nomos), sino en virtud de estar en Cristo por la fe. Éste ha sido tratado como un pasaje importante para entender que Pablo no discute si la ley (moral o ceremonial) todavía permanece o ha sido abolida. Es importante entender que el legalismo no tiene que ver con ser estricto en el cumplimiento de la ley. No es el cargo que se formula en el NT. Es 
importante evitar la deshonra de Dios que ocurre por la infracción de la ley (Rom 2:23). La obediencia plena se requiere en las Escrituras. El error del judaísmo consistió en procurar ganar la salvación mediante la obediencia a la ley. No obstante, hay un aspecto de la obediencia relacionado con la salvación. La salvación se pone en riesgo cuando se desobedece. ¿Qué diferencia existe entre decir esto o decir que se obedece para ser salvado? El error judío consistió en colocar la ley en un rol salvador que no le corresponde. Esto traiciona el mismo rol de la ley y da la oportunidad a la búsqueda de recompensa por hacer la ley. Al poner a la ley con un rol de salvadora no se la deja seguir siendo ley. Lo que sigue es una despersonalización del pecado, pues es redimible con otro acto, y así se lo maneja como pesas en una balanza. Por lo tanto, el legalismo debe entenderse no como la estrictez a la obediencia, tampoco el abrazar demasiadas normas, ni el temor al pecado. El legalismo es poner la ley como salvadora en lugar de Cristo. ${ }^{69}$

Esta cuestión es la que está causando dificultades de entender las discusiones entre la AP y la NP. Los adventistas corren riesgo de esto sólo si su observancia de la ley los lleva a hacer distinciones con otros grupos como ocurría dentro del judaísmo, como por ejemplo: circuncidado o no, las cuales no son importantes en Cristo. En forma similar, no es en virtud de ser sabatistas o guardadores de los mandamientos, o bautizados como cristianos, o vegetarianos, o adventistas que se es salvo. No es en virtud de identificarse con un grupo.

\footnotetext{
${ }^{69}$ Aecio Caïrus, La epístola a los Romanos (Libertador San Martín, Entre Ríos: Universidad Adventista del Plata, 1993), 53-54.
} 
Sino por "pistis", la propia identidad en Cristo, la fe en Cristo, la fidelidad de Cristo, o la fidelidad hacia él. Todos los significados del término griego "pistis" son importantes. La pregunta debiera ser cuál es la propia relación que el sujeto tiene con Dios.

Como ya se dijo, el énfasis restauracionista que caracterizó históricamente a los adventistas, los llevó a ser cuestionados dentro del protestantismo. Esta acusación hizo que hayan tratado de mostrar que mantenían cercanía con las propuestas protestantes sobre aspectos de la salvación en Cristo. Producto del intento por responder las inquietudes que los protestantes y evangélicos tenían respecto a los adventistas surgió el libro Seventhday Adventists Answer Questions on Doctrine. ${ }^{70}$ Este libro, aunque produjo un acercamiento con los protestantes y los evangélicos, ${ }^{71}$ fue uno de los que causó más discusiones dentro del adventismo. ${ }^{72}$

${ }^{70}$ Libro publicado por la Iglesia Adventista del Séptimo Día en 1957.

${ }^{71}$ Véase por ejemplo: Donald Grey Barnhouse ("Are Seventh-day Adventist Christians?", Eternity, septiembre de 1956, 7) que dijo que los adventistas del séptimo día eran verdaderamente un grupo cristiano y no un culto anticristiano; Billy Graham gradualmente invitó a los adventistas a participar de sus cruzadas.

${ }^{72}$ Se discutían temas como: (a) si el sacrificio de Cristo fue completado en la cruz; (b) si la salvación es el resultado de la gracia más las obras de la ley; (c) si Jesús fue un ser creado, y no existió desde la eternidad; (d) si Jesús asumió la naturaleza pecaminosa caída del hombre al encarnarse; (e) el rol de los escritos de Elena de White; (f) el rol de la ley; (g) el sábado; (h) las leyes dominicales y la marca de la Bestia; (i) las profecías de los Dan 8 y 9; (j) las doctrinas adventistas sobre el santuario celestial y el juicio investigador; (k) la segunda venida de Jesús; (l) la muerte y el infierno. Véanse el registro sobre este tema disponible en http://en.wikipedia.org/wiki/Questions_ on_Doctrine\#cite_note-5; Internet (consultada el 7 de octubre de 2013). 
Al cumplirse el $50^{\circ}$ aniversario de la publicación de Questions on Doctrine, Donald W. Dayton (de la Iglesia Wesley) comentó que la cuestión de la escatología fue quizás el tema central del siglo XIX en el cristianismo y que aquellos que develen los misterios de estas cuestiones brindarán las claves como "bisagras" para la interpretación de ese siglo en la experiencia americana. Además indica que los adventistas se anticiparon al plantear cuestiones sobre el estatus del judaísmo y el AT en la teología cristiana. Apeló a que los adventistas exploren sus propias fuentes para hacer una mirada introspectiva y así colaborar para que las tradiciones cristianas redirecciones sus inquietudes. Mencionó que el rechazo de la "inmortalidad del alma" es un paso significativo en esa dirección, por sus ideas acerca del milenio, y que los adventistas se anticiparon a las doctrinas de la NP y que ayudaron a corregir el curso de la extensa tradición. Agregó que esto es un llamado superior que el de procurar asimilarse a la tradición evangélica que parece dominar la discusión como en Questions on Doctrine. Concluyó diciendo que teme que el adventismo venda su herencia por un simple plato de potaje. ${ }^{73}$ Algo similar advirtió Aecio Caïrus con anterioridad cuando, al analizar a E. P. Sanders y su propuesta, dijo que mucho del interés en el tipo de revisionismo propuesto por Sanders "se centra en la posibilidad de mejorar las relaciones entre el protestantismo evangélico y la sinagoga, reinterpretando el Nuevo Testamento

${ }^{73}$ Donald W. Dayton, "Some Reflections on Adventist Identity by a 'Simpatyhetic Outsider' on the Fiftieth Anniversay of the Publication of Questions on Doctrine", disponible en http:/ / www.qod.andrews.edu/docs/ 10_donald_dayton.pdf; Internet (consultada el 3 de octubre de 2013). 
de modo que resulte menos ofensivo a esta última". Concluye que "algunas de las reconstrucciones del pensamiento rabínico sobre la salvación son meras caricaturas y adolecen de graves defectos" y que "aunque mejorar las relaciones entre las distintas comunidades religiosas es altamente loable, debemos cuidar de no hacerlo a expensas de la verdad. En todo tratado sobre este asunto... es necesario recurrir permanentemente a las fuentes rabínicas originales". ${ }^{74}$

Norman Gulley hizo un estudio histórico y sistemático breve donde analizó que existe una declinación en el protestantismo porque, por ejemplo los luteranos pietistas, no enfatizan la justificación forense por estar más interesados en la experiencia y se concentraron en que los creyentes sean hechos justos. Esto es similar a la teología Ortodoxa y su deseo de tener una experiencia mística con Dios, y sin un interés por la justificación por la fe. Gulley cita varios análisis de los mismos evangélicos y protestantes sobre la doctrina de la justificación por la fe, por ejemplo: ${ }^{75}$

1. Michael S. Horton concluye que el 87 porciento de los profesores de teología que dirigen instituciones evangélicas están más inclinados a practicar conceptos de los católicos sobre la relación del creyente con Dios y que es difícil actualmente encontrar que alguien crea en que la justificación por la fe sola sea verdad y mucho menos necesaria. ${ }^{76}$

${ }^{74}$ Caïrus, La epístola a los Romanos, 32-33.

${ }^{75}$ Norman Gulley, “Debate over Justification by Faith: Evangelicals and Catholics", Journal of the Adventist Theological Society, 20:1, 2 (2009) 112-134.

${ }^{76}$ Prefacio a R. C. Spoul, Faith Alone: The Evangelical Doctrine of 
2. Thomas F. Torrance expresó que se siente asombrado de ver cuán cerca se encuentran algunos grupos del punto de vista católico. ${ }^{77}$

3. Alister McGrath concluye que existen diferencias entre los protestantes y los católicos sobre cuestiones de justificación, pero que en años recientes parece aumentar la simpatía por ver estas diferencias, aunque importantes en el período de la Reforma, como siendo no tan significativas como antes. Es decir, en la actualidad las denominaciones cristianas prefieren concentrarse en puntos de vista que concuerdan, en lugar de llamar la atención a sus desacuerdos históricos. ${ }^{78}$

Los análisis desde la mirada adventista a la NP pueden interpretarse desde el cumplimiento escatológico, como el cumplimiento de profecías hechas en Ap 13 e incluso declaraciones de Elena de White en el Conflicto de los siglos y otras publicaciones. Pero también puede ser una oportunidad para estudiar en profundidad aspectos de la teología bíblica adventista relativos a la fe y la obediencia de la ley; la justificación, la expiación, el santuario y otras doctrinas relacionadas con lo

Justification (Grand Rapids, Michigan: Baker, 1995), 13, citado en Gulley, "Debate over Justification by Faith: Evangelicals and Catholics", 141.

${ }^{77}$ T. F. Torrance, Theology in Reconstruction (London: SCM, 1965), 164 citado en Gulley, "Debate over Justification by Faith: Evangelicals and Catholics", 142.

${ }^{78}$ Alister E. Mc Grath, Justification by Faith: What it Means for Us Today" (Grand Rapids, Michigan: Zondervan, 1988), 71; citado en Gulley, "Debate over Justification by Faith: Evangelicals and Catholics", 142. Nótese que McGrath escribió esto seis años antes de la declaración conjunta entre evangélicos y católicos de marzo de 1994. 
Teológico, Cristológico, Soteriológico, Antropológico y Escatológico. ${ }^{79}$

En resumen, se abre una puerta al diálogo en vista del crecimiento y mayor profundización desde la erudición de distintas iglesias cristianas en cuanto a algunos puntos en los que ellos mismos han encontrado incoherencias y con dificultades para sostenerlas desde los estudios bíblicos.

\section{Conclusión}

Como ya se comentó en la introducción de los antecedentes de este estudio, el interés por comprender la labor interpretativa en Pablo se ha incrementado en las últimas décadas. Esto se debe a las investigaciones sobre judaísmo antiguo y Qumrán que influenciaron en algunos autores produciendo un cambio en la forma de revisar la literatura bíblica y las declaraciones paulinas.

La cuestión de la Ley y la Justificación en Pablo ha sido un tema sobre el cual se ha escrito mucho. La razón de ello es su importancia en la comprensión de la teología paulina. De hecho, para varios estudiosos, la cuestión de la justificación constituye el centro mismo de la teología de Pablo. Por su parte, la Ley, siendo vista

${ }^{79}$ Véase la tesis de Silvia C. Scholtus, “La influencia de la hermenéutica tannaíta en la argumentación paulina de Romanos 1 al 5" (Tesis presentada para su defensa en la Facultad de Teología de la Universidad Adventista del Plata, Libertador San Martín, Entre Ríos, febrero 2014). Esta tesis repasa varios aspectos del primer siglo en cuanto a presupuestos macro, meso y micro hermenéuticos tannaítas y los compara con la forma de argumentación paulina en los primeros cinco capítulos de Romanos mostrando su estrecha similitud en cuanto a presupuestos, procedimientos, técnicas y formas de argumentación. 
como un impedimento o rival de Cristo en la justificación, ha tenido por ello también un lugar importante en el estudio de la teología paulina. Sin embargo, los numerosos estudios que se han hecho, no han llevado a un consenso general, sobre todo por lo que concierne a la cuestión de la Ley.

Las preguntas sobre los temas controvertidos aún siguen vigentes como: ¿Cuál es el significado de la pa-

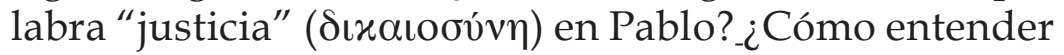

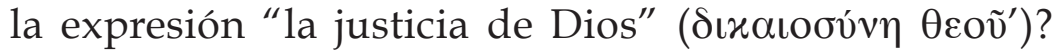

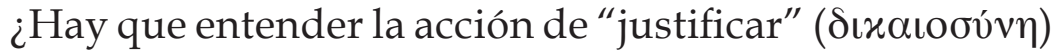
en el sentido de una simple declaración de parte de Dios (sentido jurídico) o bien como una transformación real de la persona humana (sentido efectivo)? ¿Por qué la justificación no puede ser obtenida por medio de la observancia de la Ley?

La puerta para un estudio más profundo de los temas paulinos mencionados sigue abierta y desafía. 